ARTICULO DE INVESTIGACION

\title{
Proliferación de embriones somáticos de Nothofagus alpina: efecto de la fuente de nitrógeno orgánico exógena
}

\author{
Proliferation of somatic embryos of Nothofagus alpina: \\ effect of an exogen source of organic nitrogen
}

\author{
Hermes Castellanos ${ }^{1}$, Darcy Ríos², Manuel Sánchez-Olate2, \\ Christian Wehenkel ${ }^{1}$ y Javier Corral ${ }^{3}$
}

\begin{abstract}
RESUMEN
Se probó el efecto de algunas fuentes de nitrógeno orgánico como caseína hidrolizada y los aminoácidos L-Glutamina y L-Serina en el proceso de embriogénesis somática secundaria directa, empleando como explantes embriones somáticos de Nothofagus alpina inducidos desde cotiledones aislados de semillas maduras. Los mayores porcentajes de embriogénesis secundaria directa fueron obtenidos en medio base BTM y vitaminas MS, sin reguladores del crecimiento vegetal y en este medio más ANA, BAP y caseína hidrolizada. Sin embargo, el peso fresco de las masas de proliferación fue superior en presencia de una fuente adicional de nitrógeno orgánico. Bajo el tratamiento con reguladores del crecimiento y caseína hidrolizada también se produjo la mayor cantidad promedio de embriones producidos por explanto, aunque no hubo diferencias significativas con el tratamiento que contuvo L-Glutamina, donde el crecimiento de callo fue significativamente menor. Mediante subcultivos alternados entre medio base y medio con ANA, BAP y caseína hidrolizada, se logró la proliferación del cultivo embriogénico de manera directa, estable durante más de dos años y con baja incidencia de callo.
\end{abstract}

PALABRAS CLAVE:

Embriogénesis somática, estado de desarrollo, micropropagación, reguladores del crecimiento.

\begin{abstract}
The effect of some sources of organic nitrogen such as hydrolyzed casein and the aminoacids L-glutamine and L-Serine were tested in the process of direct secondary somatic embryogenesis, in which somatic embryos of Nothofagus alpina -induced from isolated cotyledons of mature seeds- were used as explants. The highest percentages of direct secondary embryogenesis were obtained in BTM base medium plus MS vitamins, without plant growth regulators, and in this medium plus NAA, BAP and hydrolyzed casein. However, the fresh weight of the proliferated mass was greatest in the presence of an additional source of organic nitrogen. The highest average number of embryos per explant was also produced in the treatment with growth regulators and hydrolyzed casein, although the number was not significantly higher than in the L-Glutamine treatment, in which significantly less callus growth occurred. Alternate use of base medium and NAA, BAP and hydrolyzed casein medium during subcul-
\end{abstract} tera a Mazatlán. Durango, Dgo. México. CP 34120.

2 Laboratorio Cultivo de Tejidos Vegetales. Centro de Biotecnología. Universidad de Concepción, Chile.

3 Facultad de Ciencias Forestales, Universidad Juárez del Estado de Durango, Río Papaloapan y Blvd. Durango s/n, Col. Valle del Sur, CP 34120, Durango, México 
ture enabled direct proliferation of the embryogenic culture, which remained stable for over two years and with a low incidence of callus.

\section{KEYWORDS:}

Somatic embryogenesis, developmental stage, micropropagation, growth regulators.

\section{INTRODUCCIÓN}

Nothofagus alpina (Poepp. et Endl.) Oerst.) (raulí), es considerada la especie nativa del bosque chileno con mayor potencial productivo, la que se produce mayormente mediante semillas para repoblación artificial (Donoso et al., 1998). Salvo contadas excepciones, como aquellas para promover el mejoramiento genético y la silvicultura clonal del raulí y otros Nothofagus (Gutiérrez, 2005), la regeneración de esta especie con fines productivos se ha llevado a cabo mediante el manejo de renovales o bosques de segundo crecimiento (Donoso, 1978), lo cual, si bien tiene un efecto positivo en la calidad de los renuevos, no explota a cabalidad el acervo genético de la especie para fines productivos y de conservación.

Para la propagación de la especie, junto con la vía generativa para obtener semilla mejorada genéticamente a través de polinización controlada (Ipinza y Gutiérrez, 2000), se ha explorado la propagación vegetativa, tanto mediante macro como micropropagación organogénica. Estas investigaciones han logrado resultados prometedores (Jordan et al., 1996; Martínez-Pastur y Arena, 1996; SánchezOlate et al., 2004), pero han demostrando las limitaciones técnicas como bajas tasas de enraizamiento y escasa aplicabilidad a nivel operacional que surgen al pretender aplicar este tipo de alternativas para propagación en programas operativos de reforestación.
Gran parte de estas limitaciones puede ser superada mediante el establecimiento de micropropagación basado en la embriogénesis somática, que es la regeneración de un embrión a partir de células o tejidos somáticos diferenciados, constituyendo la expresión máxima de la totipotencia de la célula vegetal, como resultado del aislamiento, tanto espacial como fisiológico, de una célula o grupo celular (Toribio, 2003; Fehér, 2006). Actualmente, se ha conseguido inducir con éxito la embriogénesis somática en un número cada vez mayor de especies y explantos de inicio, principalmente en coníferas como Pinus taeda, Abies alba y Larix decidua, lo que ha propiciado su aplicación a escala operacional para la propagación masiva de genotipos selectos (Zoglauer et al., 2003). En el caso de $N$. alpina se ha conseguido inducir exitosamente masas proembriogénicas y regeneración de embriones somáticos viables desde explantos cotiledonares extraídos desde semillas maduras provenientes del huerto semillero clonal Huillilemu, ubicado en la provincia de Valdivia, décima región de Chile (Castellanos et al., 2005).

Algunas fuentes de nitrógeno orgánico como aminoácidos y caseína hidrolizada, han sido probadas en leñosas y herbáceas logrando una proliferación sostenida de estructuras embriogénicas in vitro y más aún su posterior conversión a planta (Kim y Moon, 2007; Sarker et al., 2007; Corredoira et al., 2003), no así en sistemas embriogénicos de Nothofagus alpina. Dichos aditivos en el medio de cultivo, en presencia o ausencia de sales de nitrógeno inorgánica incrementan la eficiencia del cultivo en la embriogénesis somática, lo cual se manifiesta en mayores tasas de multiplicación de embriones y retención del potencial embriogénico de los tejidos (Sotiropoulos et al., 2005). 


\section{OBJETIVOS}

La disparidad de resultados entre géneros y especies frente a un mismo estímulo de cultivo in vitro, hacen necesario la búsqueda para cada caso en particular de la mejor secuencia de cultivo que asegure la obtención de un protocolo de regeneración confiable. Así, el objetivo de este trabajo fue indagar la dosis de aminoácidos, adicionales a los contemplados en el medio de cultivo base, así como la incorporación de caseína hidrolizada, a fin de incrementar los niveles de proliferación de nuevas estructuras embriogénicas en la línea clonal RaC-01 de Nothofagus alpina, una de las tres líneas clonales inducidas con éxito desde cotiledones de semillas maduras y que se ha mantenido con niveles de proliferación estables hasta la fecha.

\section{METODOLOGÍA}

Material vegetal. El material empleado en este estudio se obtuvo del cultivo de la línea embriogénica RaC-01 (raulí, explanto cotiledonar, línea clonal 01), inducida desde cotiledones aislados de semillas maduras de $N$. alpina, las cuales se generaron en un huerto semillero clonal del Instituto Forestal de Chile (Infor), mediante polinización controlada. Luego de la inducción de masas preembriogénicas (MPEs) y manifestación de embriones somáticos, el cultivo se mantuvo en medio de manutención, consistente en la solución mineral Broadleaved Tree Medium o BTM (Chalupa, 1983) y vitaminas MS (Murashige y Skoog, 1962), más los reguladores del crecimiento 6-benciladenina (BA) y ácido $\alpha$-naftalenacético (ANA) a concentraciones de $0,1 \mathrm{mgL}^{-1}$ cada uno, así como $30 \mathrm{gL}^{-1}$ de sacarosa y $6 \mathrm{gL}^{-1}$ de agar. Cada 28 días se realizó un subcultivo a medio fresco, alternándose dos subcultivos con los reguladores del crecimiento (RC) y concentraciones mencionados anteriormente con un subcultivo en medio base BTM, sin RC.

Explantos de inicio. Con ayuda de material quirúrgico previamente esterilizado y bajo lupa estereoscópica, se aislaron desde las MPEs los explantos que sirvieron de material de inicio para cada uno de los tratamientos. Dichos explantos correspondieron a embriones somáticos primarios en estado cotiledonar (ESP), seleccionando aquellos de morfología normal y con una longitud de eje embrionario de entre $3 \mathrm{~mm}$ y $4 \mathrm{~mm}$ (Figura 1a).

Tratamientos de proliferación. Se aplicaron seis tratamientos de proliferación (incluyendo un testigo en media base $\sin \mathrm{RC}$ ). El medio base aplicado a todos los tratamientos correspondió a la solución mineral BTM con vitaminas MS. En los tratamientos que incluyeron reguladores del crecimiento (T3, T4, T5 y T6), se aplicó BAP y ANA en relación 1:1. A su vez, se agregó al medio de cultivo caseína hidrolizada y los aminoácidos L-Glutamina y L-Serina, en las concentraciones y combinaciones que se detallan en la tabla 1 y que constituyen los tratamientos ensayados.

Condiciones de cultivo. El pH en todos los tratamientos fue ajustado a 5,8 por medio de la aplicación de $\mathrm{HCl}$ o $\mathrm{NaOH}$, antes de su esterilización en autoclave a $121^{\circ} \mathrm{C}$ y 1 atmósfera de presión, durante 20 minutos. Todos los tratamientos estuvieron con $30 \mathrm{gL}^{-1}$ de sacarosa y $6,0 \mathrm{gL}^{-1}$ de agar. A lo largo de las seis semanas del experimento, el cultivo se mantuvo en oscuridad continua a una temperatura de $(25 \pm 1){ }^{\circ} \mathrm{C}$ de día (16 horas, fotoperiodo en la cámara de cultivo) y $(22 \pm 1)^{\circ} \mathrm{C}$ de noche. 
Tabla 1. Soluciones minerales y reguladores del crecimiento aplicados en los tratamientos de proliferación de la línea embriogénica de raulí RaC-01.

\begin{tabular}{|c|c|c|c|c|c|}
\hline \multirow[t]{2}{*}{ Tratamiento } & \multicolumn{2}{|c|}{$R C\left(m g L^{-1}\right)$} & \multicolumn{3}{|c|}{ Otros componentes $\left(m^{\prime-1}\right)$} \\
\hline & ANA & $B A P$ & Caseina hid. & L-Glutamina & L-Serina \\
\hline $\mathrm{T} 1$ & 0,0 & 0,0 & - & - & - \\
\hline $\mathrm{T} 2$ & 0,0 & 0,0 & 500 & - & - \\
\hline T3 & 0,05 & 0,05 & - & - & - \\
\hline $\mathrm{T} 4$ & 0,05 & 0,05 & 500 & - & - \\
\hline T5 & 0,05 & 0,05 & - & 2,0 & - \\
\hline T6 & 0,05 & 0,05 & - & - & 2,0 \\
\hline
\end{tabular}

Diseño experimental y análisis estadístico. Se estableció un diseño experimental completamente al azar. La unidad experimental correspondió a una placa petri de $9 \mathrm{~cm}$ de diámetro, conteniendo nueve ESP, con cinco repeticiones. La unidad muestral correspondió a cada ESP. Al cabo de seis semanas se evaluó el porcentaje de explantos (ESP) con embriogénesis secundaria directa (ESSD), porcentaje de explantos con callogénesis, número de embriones somáticos secundarios (ESS) en estado cotiledonar y torpedo por ESP y peso fresco $(\mathrm{mg})$ del macizo de proliferación.

Debido a la naturaleza del experimento, con un limitado número de repeticiones y al incumplimiento del supuesto de normalidad de las observaciones, se llevó a cabo un análisis no paramétrico basado en permutaciones (Manly, 1997) con el fin de verificar si las diferencias observadas entre los valores promedio de los tratamientos se deben a un efecto dirigido de estos, o bien a eventos al azar (Wehenkel et al., 2008). Mediante un elevado número de permutaciones es posible evaluar las diferencias promedio entre los tratamientos, las cuales sean mayores o iguales que las respectivas diferencias observadas, lo que se llevó a cabo para las cinco variables antes mencionadas.

\section{RESULTADOS}

Embriogénesis somática secundaria directa (ESSD). Los efectos de la aplicación de tratamientos de proliferación comienzan a evidenciarse a los cinco días de iniciado el ensayo, manifestándose de dos formas diferentes. En primer lugar, algunos explantos de inicio (ESP, Figura 1a) comienzan a experimentar un aumento de tamaño tanto en sentido radial como longitudinal, seguido de la ruptura del tejido epidérmico en ambos polos de crecimiento longitudinal para luego dar paso a una continua proliferación celular, la cual, a las dos semanas cubre toda la superficie del explanto (Figura 1b). El segundo tipo de respuesta es la ocurrencia de germinación del ESP y elongación del eje hipocótilo-raíz. Conjuntamente se aprecia la aparición de agregados celulares blancos y cristalinos en la región hipocótilo, así como de pequeñas estructuras sobre el tejido epidérmico 


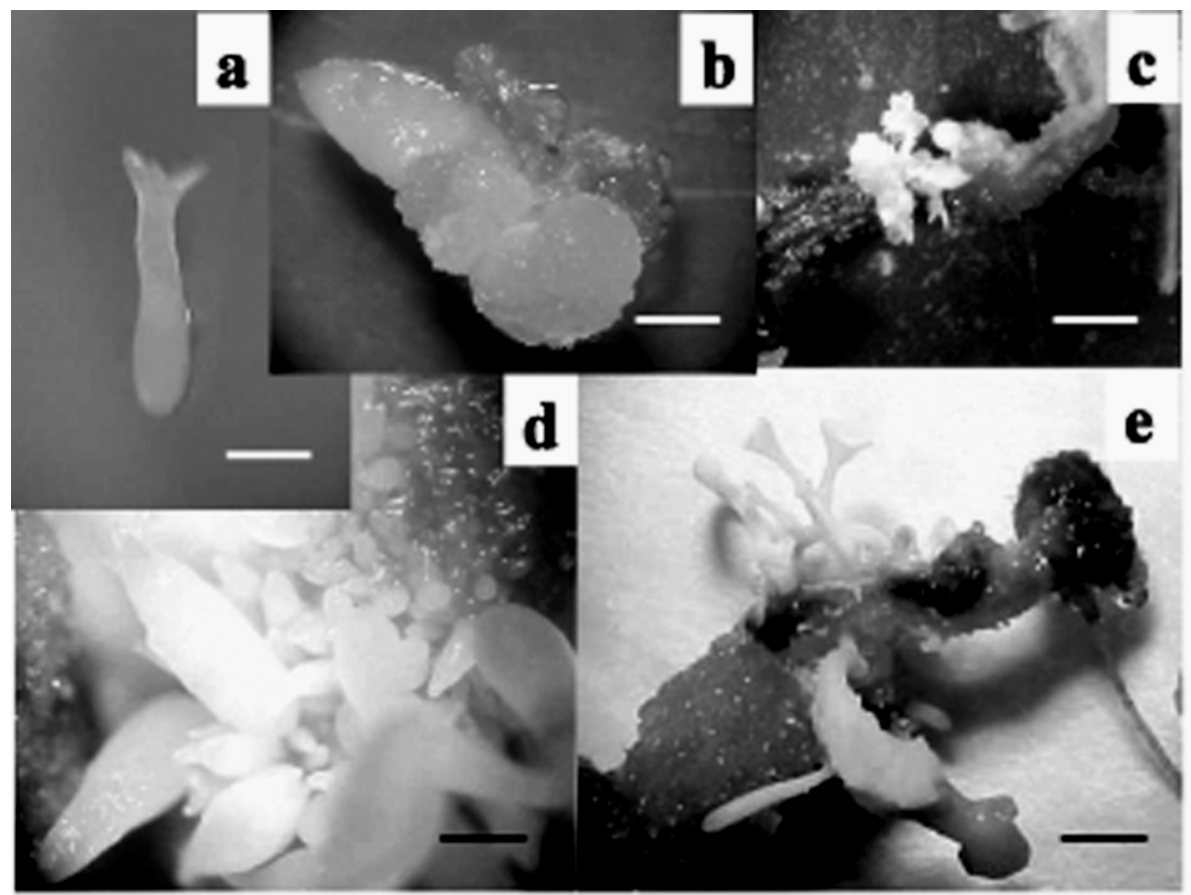

Figura 1. Diferentes aspectos de la proliferación de embriones somáticos de Nothofagus alpina. a) Explanto de inicio, embrión somático (ESP) en estado cotiledonar.

b) Respuesta callogénica desde ESP. c) Embriogénesis somática directa desde la región hipocótilo de un ESP. d) ESS en estado globular, torpedo y cotiledonar emergiendo directamente desde ESP. e) Embriones somáticos en estado cotiledonar.

solo observables bajo lupa, correspondientes a embriones somáticos secundarios en estado globular generados de manera directa, los cuales a las cuatro semanas serán perfectamente identificables a simple vista (Figura 1c).

Respecto al porcentaje de explantes presentando (ESSD), se determinaron efectos significativos de los tratamientos aplicados sobre esta variable, alcanzándose un máximo de $53,3 \%$ de explantos iniciales, lo cual ocurrió en el tratamiento T5, el cual contiene $2,0 \mathrm{mgL}^{-1}$ de L-Glutamina además de los reguladores del crecimiento ANA y BAP (Tabla 2). Sin embargo, este tratamiento no difiere significativamente con el tratamiento testigo en medio BTM ni con el tratamiento T4 que contiene RC más caseína hidrolizada.

El tratamiento en que menos explantos manifestaron embriogénesis somática directa fue en el que se adicionó 2,0 $\mathrm{mgL}^{-1}$ del aminoácido L-Serina en combinación con ANA y BAP, con un $4,4 \%$ en tal condición.

Callogénesis. Los tratamientos aplicados influenciaron significativamente la respuesta en formación de callo desde los explantos de inicio. El mayor porcentaje de formación de callo se obtuvo en el tratamiento T3 (80\%) con los reguladores del crecimiento ANA y BAP a una concen- 
tración de 0,05 $\mathrm{mgL}^{-1}$ cada uno, sin otro suplemento adicional. Esta respuesta no difiere significativamente agregando 500 $\mathrm{mgL}^{-1}$ de caseína hidrolizada a estas condiciones (T4), donde $73.4 \%$ de los explantes presentaron callo (Tabla 3). Los niveles de callogénesis se presentaron significativamente inferiores a los tratamientos antes mencionados, principalmente bajo dos condiciones (Tabla 3): sin reguladores del crecimiento (con o sin caseína hidrolizada, T1 y T2) y con RC más aminoácidos (T5 y T6).

De acuerdo con lo observado en el sistema embriogénico en $N$. alpina, el mayor porcentaje de ESS morfológicamente normales se presenta por la vía directa, por lo que se considera favorable que la incidencia de callo se mantenga en niveles bajos en los tratamientos en donde se observaron los mayores índices de ESSD (T1 y T5, Tabla 2), esto debido a que en ausencia de callo los embriones se presentan morfológicamente normales, con ambos cotiledones y pueden ser aislados con mayor facilidad para las siguientes etapas de maduración y germinación.

Número de embriones somáticos secundarios (ESS). En esta variable en que se considera ESS tanto en estado torpedo como cotiledonar (Figura 1d), los tratamientos influenciaron significativamente los resultados, luego de seis semanas de iniciado el ensayo. La mayores cantidades de ESS por explante se generaron en tratamientos con reguladores del crecimiento, con excepción del T6 donde el aminoácido L-Serina está presente. El mayor nivel se presentó en el tratamiento T4 con un promedio de 2.6 ESS por explanto, sin diferir significativamente con el número de ESS promedio alcanzado en los tratamientos T3 y T5, con 2.2 embriones somáticos secundarios en ambos casos (Tabla 4). Los resultados en los tratamientos antes mencionados tuvieron diferencias significativas con el resto.

Tabla 2. Valores de probabilidad (p) mediante 10000 permutaciones y porcentajes de embriogénesis somática secundaria directa (ESD) en tratamientos aplicados a embriones somáticos primarios (ESP) de Nothofagus alpina.

\begin{tabular}{llllll}
\hline Tratamiento & $T 1$ & $T 2$ & $T 3$ & $T 4$ & $T 5$ \\
\hline T2 & 0,155 & & & & \\
T3 & $0,044^{*}$ & 0,576 & & & \\
T4 & 0,092 & 0,330 & 0,333 & & \\
T5 & 0,374 & $0,037^{*}$ & $0,039^{*}$ & 0,062 & \\
T6 & $0,004^{\star *}$ & 0,074 & $0,042^{*}$ & $0,009^{* *}$ & $0,002^{* *}$ \\
& Embriogénesis somática secundaria directa (ESSD) $\%$ & \\
\hline T1 & $T 2$ & $T 3$ & $T 4$ & $T 5$ & $T 6$ \\
\hline 46,7 & 22,2 & 22,2 & 28,9 & 53,3 & 4,4 \\
\hline
\end{tabular}


Tabla 3. Valores de probabilidad mediante 10000 permutaciones y porcentajes de callogénesis en tratamientos aplicados a embriones somáticos primarios (ESP).

\begin{tabular}{|c|c|c|c|c|c|}
\hline Tratamiento & $T 1$ & $T 2$ & T3 & T4 & T5 \\
\hline T2 & 0,120 & & & & \\
\hline T3 & $0,004^{* *}$ & $0,004^{* *}$ & & & \\
\hline $\mathrm{T} 4$ & $0,004^{* *}$ & $0,004^{* *}$ & 0,274 & & \\
\hline T5 & 0,549 & 0,094 & $0,002^{\star *}$ & $0,002^{* *}$ & \\
\hline T6 & $0,034^{*}$ & 0,652 & $0,002^{* *}$ & $0,002^{* *}$ & $0,024^{*}$ \\
\hline \multicolumn{6}{|c|}{ Callogénesis \% } \\
\hline T1 & $T 2$ & T3 & $T 4$ & T5 & T6 \\
\hline 26,6 & 11,1 & 80,0 & 73,4 & 31,1 & 13,3 \\
\hline
\end{tabular}

Nota: * valores significativos $(p<0,05) ;{ }^{* *}$ valores altamente significativos $(p<0,01)$

Tabla 4. Valores de probabilidad ( $p$ ) mediante 10000 permutaciones y número de embriones somáticos secundarios por explanto en tratamientos aplicados a embriones somáticos primarios.

\begin{tabular}{llllll}
\hline Tratamiento & $T 1$ & $T 2$ & $T 3$ & $T 4$ & $T 5$ \\
\hline T2 & 0,082 & & & \\
T3 & $0,037^{*}$ & $0,004^{* *}$ & & & \\
T4 & $0,039^{*}$ & $0,004^{* *}$ & 0,436 & & \\
T5 & $0,039^{*}$ & $0,004^{* *}$ & 0,660 & 0,439 & \\
T6 & 0,258 & 0,501 & $0,012^{*}$ & $0,011^{*}$ & $0,011^{*}$ \\
& & & & \\
\hline$T 1$ & Número de embriones somáticos secundarios & & $T 6$ \\
\hline 1,2 & 0,4 & $T 3$ & $T 4$ & $T 5$ & 0,4 \\
\hline
\end{tabular}

Nota: * valores significativos $(p<0,05) ;{ }^{* *}$ valores altamente significativos $(p<0,01)$ 
Considerando solo ESS en estado cotiledonar, la mayor cantidad por explante se presentó nuevamente en el T4 con un promedio de 1,6 sin presentar diferencias significativas, solo con T3 en donde este promedio alcanzó los 1,5 ESS por ESP $(p=0,498)$. Los ESS en estado cotiledonar se presentan en su mayoría con caracteres morfológicos normales, principalmente en lo referido al par cotiledonar. Los ESS con anormalidades morfológicas tales como presencia de cotiledones fusionados, no supera $20 \%$ del total, en el T4.

Peso fresco. El peso fresco de los agregados embriogénicos también se vio influenciado significativamente por los tratamientos. Esta variable se presentó en mayor magnitud en los tratamientos T3 y T4 (33,2 y 27,9 mg, respectivamente), sin diferencias significativas entre ambos tratamientos $(p=0,163)$, pero sí con el resto de los tratamientos probados (Tabla 5). En los tratamientos T3 y T4 no existió una dosis adicional de aminoácidos, salvo la adición de ANA y BAP y caseína hidrolizada. Esta respuesta está influenciada tanto por la mayor presencia de callo en estos tratamientos, así como por la mayor cantidad de ESS en estado cotiledonar (Figura 1e).

Los valores menores de esta variable se presentaron en tratamientos sin reguladores del crecimiento ( $\mathrm{T} 1$ y $\mathrm{T} 2$ ), así como en el tratamiento T6 que contiene L-Serina, sin superar los $10 \mathrm{mg}$ por macizo embriogénico en promedio.

Por otra parte, la supervivencia de los explantos se mantuvo alta en todos los tratamientos a lo largo del estudio, presentando valores máximos $(100 \%)$ en los tratamientos T4 y T5, lo cual difiere significativamente con el tratamiento que contiene L-Serina (T6), que tuvo en promedio $86,7 \%$ de supervivencia.

Tabla 5. Valores de probabilidad $(\mathrm{p})$ mediante 10000 permutaciones y peso fresco $(\mathrm{mg})$ de los macizos de proliferación embriogénica en tratamientos aplicados a embriones somáticos primarios (ESP).

\begin{tabular}{llllll}
\hline Tratamiento & $T 1$ & $T 2$ & $T 3$ & $T 4$ & $T 5$ \\
\hline T2 & 0,276 & & & & \\
T3 & $0,004^{* *}$ & $0,004^{* *}$ & & & \\
T4 & $0,004^{* *}$ & $0,004^{* *}$ & 0,163 & & \\
T5 & $0,044^{*}$ & $0,026^{*}$ & $0,004^{* *}$ & $0,004^{* *}$ & \\
T6 & 0,392 & 0,407 & $0,004^{* *}$ & $0,004^{* *}$ & 0,084 \\
& & & & & \\
\hline$T 1$ & Peso fresco $(\mathrm{mg})$ & & $T 4$ & $T 6$ \\
\hline 7,7 & 6,8 & $T 3$ & 28,0 & 10,8 & 7,4 \\
\hline
\end{tabular}




\section{DISCUSIÓN Y CONCLUSIONES}

Si bien es cierto que las plantas, a diferencia de los humanos y la mayoría de los animales, son capaces de sintetizar todos los aminoácidos derivados de las proteínas a partir de moléculas como el piruvato y el ciclo del ácido cítrico (Taiz y Zeiger, 2006), tales componentes orgánicos se agregan a los medios de cultivo para satisfacer requerimientos de nitrógeno en su forma reducida. Estos se emplean de manera rutinaria cuando su efecto es positivo en sistemas de micropropagación masiva, como la embriogénesis somática, a pesar de su alto costo (George y de Klerk, 2008).

Se ha comprobado el efecto positivo de la adición de caseína hidrolizada y otras fuentes orgánicas de nitrógeno como los aminoácidos L-Glutamina y L-Serina a los medios de cultivo en diferentes fases de la embriogénesis somática, incluyendo inducción y proliferación de MPE, atribuyéndoles entre otros efectos, incrementar el número de nuevas estructuras embriogénicas y promover su desarrollo (Varisai et al., 2004).

Por su parte, la caseína y otras proteínas hidrolizadas son menos costosas, aunque debido a su origen y procesos de obtención, son de naturaleza menos definida que los aminoácidos, lo cual implica que se deba probar su eficiencia en cada sistema embriogénico en particular. La caseína hidrolizada constituye una fuente de calcio, fosfato, diversos microelementos, vitaminas y una mezcla de al menos 18 aminoácidos, entre ellos la glutamina. Se ha probado su efecto estimulador del desarrollo en procesos morfogénicos in vitro, tanto en procesos como el cultivo de suspensiones celulares, como en organogénesis (George y de Klerk, 2008).
El aminoácido L-Glutamina ha sido empleado con éxito en otros sistemas embriogénicos de especies leñosas, observándose un incremento en los niveles de proliferación de MPE. Tal es el caso de un estudio llevado a cabo en Abies nordmanniana (Stev.) Stach., en el cual además se adicionó caseína hidrolizada al medio de cultivo (Norgaard y Krogstrup, 1991). Las fuentes de nitrógeno orgánico suplementarias al medio de cultivo se aplican rutinariamente en estudios de embriogénesis somática en fagáceas, principalmente en las fases de inducción y proliferación de agregados embriogénicos (Cuenca et al., 1999; Xing et al., 1999). En Quercus acutissima Carruth., se adicionó $1 \mathrm{gL}^{-1}$ de L-Glutamina al medio de inducción, en el cual se cultivaron como explantos embriones cigóticos inmaduros, obteniéndose posteriormente la germinación y conversión a planta de ES de diferentes genotipos (Kim et al., 1997).

Este mismo aminoácido fue aplicado con éxito como aditivo al medio MS modificado, en la manutención de la competencia embriogénica de cultivos de Castanea sativa Mill., en donde se emplearon ES como explante para generar embriogénesis somática recurrente, con el fin de realizar estudios posteriores del efecto de la fuente de carbono en la maduración y germinación de embriones somáticos (Corredoira et al., 2003). En este estudio en $N$. alpina, la adición de aminoácidos al medio de cultivo base no tuvo un efecto significativo en relación al tratamiento testigo en cuanto a la incidencia de ES secundaria y mantenimiento de la líneas embriogénicas.

Por su parte, Robichaud et al. (2004) emplearon caseína hidrolizada $\left(1 \mathrm{gL}^{-1}\right)$ como componente adicional en medio base WPM en un estudio sobre el efecto de la adición de los aminoácidos L-Glutamina y L-Asparagina, además de agentes 
modificadores del potencial osmótico del medio, sobre la maduración de ES de Castanea dentata (Marsh.) Borkh., encontrándose, a diferencia de este estudio, que hubo un efecto positivo en el tamaño de los ES respecto al testigo, aunque también se evidenciaron anormalidades morfológicas y germinación precoz.

De acuerdo con Inoue y Maeda (1982, citados por George y De Klerk, 2008), en diversos cultivos la caseína hidrolizada es más efectiva en promover el desarrollo que la adición individual de aminoácidos en el medio de cultivo, supuestamente debido a la presencia de algún factor del crecimiento desconocido, aún presente en esa sustancia.

Si bien se considera que el mayor efecto de estas fuentes de nitrógeno inorgánico se manifiesta en soluciones minerales con baja dotación de iones $\mathrm{NH}_{4}{ }^{+}$, George y De Klerk (2008) sugieren que estas sustancias son también efectivas en medios ricos en iones amonio, debido a la conservación de la molécula de ATP (compensando la deficiencia de fosfato), su capacidad para actuar como agentes quelantes, favorecer la capacidad de asimilación de nitrógeno, sustitución de posibles iones $\mathrm{NH}_{4}{ }^{+}$tóxicos y el ajuste del $\mathrm{pH}$ intracelular.

En este estudio, el porcentaje de explantes presentando embriogénesis secundaria directa no fue afectado significativamente al agregar reguladores del crecimiento al medio de cultivo (T1 vs T4 y T5). Sin embargo, en presencia de BAP y ANA y una fuente de nitrógeno orgánico como caseína hidrolizada, el peso fresco de los macizos de proliferación y el número de ES por explante en estado cotiledonar y torpedo fueron significativamente superiores respecto al testigo. La aplicación de L-serina tuvo una incidencia negativa en esta respuesta frente al trata- miento testigo, así como frente al tratamiento que contempló adición de L-Glutamina. Por su parte, el porcentaje de incidencia de callogénesis (proliferación de MPE), así como el peso fresco de los agregados, fueron influenciados positivamente mediante la adición de BAP y ANA, con o sin caseína hidrolizada (T3 y T4).

Del mismo modo, la generación por vía directa de embriones somáticos en estado cotiledonar y torpedo fue significativamente mayor en medio con BAP y ANA sin otros componentes adicionales, excepto al adicionar caseína hidrolizada. Se recomienda la proliferación directa de embriones somáticos secundarios en Nothofagus alpina, en medio base sin RC, sin un incremento significativo en la proliferación callogénica. Sin embargo, es necesario estudiar los efectos de una fuente de nitrógeno orgánico como caseína hidrolizada y el aminoácido L-Glutamina en etapas posteriores como la maduración y germinación de embriones somáticos de raulí.

\section{RECONOCIMIENTOS}

Los autores agradecen a CONICYT-Chile y al proyecto MESESUPAUS 0103 por el financiamiento otorgado para la realización de esta investigación.

\section{REFERENCIAS}

Castellanos, H., M. Sánchez-Olate y D. Ríos. 2005. La embriogénesis somática como alternativa para la regeneración in vitro de raulí y roble. In: B. Gutiérrez, O. Ortiz y M.P. Molina. Clonación de raulí: estado actual y perspectivas. CEFOR-INFOR-UACH. Concepción, Chile. 174 p.

Cuenca, B., M. San-José, M. Martínez, A. Ballester y A. Vieitez. 1999. Somatic 
embryogenesis from stem and leaf explants of Quercus robur L. Plant Cell Reports 18:538-543.

Chalupa, V. 1983. Micropropagation of conifer and broadleaved forest trees. Communicationes Instituti Forestalis Cechosloveniae 13:7-39.

Corredoira, E., A. Ballester y A.M. Vieitez. 2003. Proliferation, maturation and germination of Castanea sativa Mill. Somatic embryos originated from leaf explants. Annals of Botany 92(1): 129-136.

Donoso, P., M. González, B. Escobar, I. Basso y L. Otero. 1998. Viverización y plantación de Raulí, Roble y Coigüe en Chile. In: C. Donoso y A. Lara. Silvicultura de los bosques nativos de Chile. Editorial Universitaria. Santiago. Chile. $421 \mathrm{p}$.

Fehér, A. 2006. Why somatic plant cells start to form embryos? In: A. Mujib y J. Samaj. Plant Cell Monographs. Somatic Embryogenesis. Springer. Alemania. 357 p.

George, E.F. y G.-J. De Klerk. 2008. The components of plant tissue cultura media I: Macro and Micronutrients. In: E.F. George, M. Hall y G.-J. De Klerk (Eds.). Plant propagation by tissue culture. Springer. Países Bajos. 501 p.

Hartmann, H. y J. Kester. 1997. Plant Propagation. Principles and Practices. Prentice Hall. EUA. 770 p.

Gutiérrez, B. 2005. Propagación vegetativa y silvicultura clonal: antecedentes generales. In: B. Gutiérrez, O. Ortiz y M.P. Molina (Eds.). Clonación de raulí: estado actual y perspectivas. CEFOR-INFOR-UACH. Concepción, Chile. 174 p.
Ipinza, R. y B. Gutiérrez. 2000. Estrategia de mejora genética para $N$. alpina y $N$. obliqua en Chile. In: R. Ipinza, B. Gutiérrez y V. Emhart (Eds.). Domesticación y mejora genética de raulí y roble. Universidad Austral de Chile, Instituto Forestal. Valdivia, Chile. 468 p.

Jordan, M., J. Velozo y A.M. Sabja. 1996. Organogenesis in vitro of Nothofagus alpina (P. et E.) Oerst., Fagaceae. Plant Cell Reports 15(10):795-798.

Kim, Y.W. y H.K. Moon. 2007. Enhancement of somatic embryogenesis and plant regeneration in Japanese larch (Larix leptolepis). Plant Cell Tissue and Organ Culture 88:241-245.

Manly, B.F.J. 1997. Randomization, bootstrap and Monte Carlo methods in biology. Segunda edición. Chapman \& Hall. 399 p.

Martínez, O. 1993. Nuevo límite sur del área de distribución de Nothofagus alpina (Mull.) Dim., Fagaceae. Bosque 14(1):73-74.

Martínez-Pastur, G. y M. Arena. 1996. In vitro propagation of Nothofagus nervosa (Phil.) Dim. et Mil. Phyton 58(1/2):1-7.

Murashige, T. y F. Skoog. 1962. A revised medium for rapid growth and bioassays with tobacco tissue culture. Physiologia Plantarum 15:473-479.

Norgaard, J. y P. Krogstrup. 1991. Cytokinin induced somatic embryogenesis from immature embryos of Abies nordmanniana Lk. Plant Cell Reports 9(9): 509-513.

Robichaud, R.L., C.L. Veronica y S.A. Merkle. 2004. Treatments affecting maturation and germination of American chestnut somatic embryos. 
Journal of Plant Physiology. 161:957969. Donoso, C. 1978. La silvicultura de Nothofagus en Chile. Departamento de Silvicultura y Conservación. Universidad de California. Berkeley. California. $102 \mathrm{p}$.

Sánchez-Olate, M., D. Ríos, M. Pedraza, G. Pereira, H. Castellanos y R. Escobar. 2004. Propagación in vitro de Nothofagus procera ((Poepp. et Endl.) Oerst.) a partir de embriones aislados. Bosque 25(1):123-128.

Sarker, K.K., A.H. Kabir, S.A. Sharmin, Z. Nasrin and M.F. Alam. 2007. Improved somatic embryogenesis using Lasparagine in wheat (Triticum aestivum L.). Sjemenarstvo 24:187-196.

Sotiropoulos, T.E., K.N. Dimassi y I.N. Therios. 2005. Effects of L-rginine and L-cysteine on growth, and chlorophyll and mineral contents of shoots of the apple rootstock EM 26 cultures in vitro. Biologia Plantarum 49(3):443-445.

Taiz, L. y E. Zeiger. 2006. Plant Physiology. Sinauer Associates, Inc. Massachusetts. 764 p.

Toribio, M. 2003. Embriogénesis somática en especies forestales. In: V Reunión de la Sociedad Española de Cultivo in vitro de Tejidos Vegetales. Pamplona. España. 131 p.
Varisai, S., C. Wang, M. Thiruvengadam y N. Jayabalan. 2004. In vitro plant regeneration via somatic embryogenesis through cell suspension cultures of horsegram (Macrotyloma uniflorum (Lam.) Verdc). In Vitro Cellular and Developmental Biology-Plant 40:284-289.

Wehenkel, A., M. Bellinzoni, M. Graña, R. Duran, A. Villarino, P. Fernandez, G. Andre-Leroux, P. England, H. Takiff, C. Cerveñansky, S.T. Cole y P.M. Alzari. 2008. Mycobacterial Ser/Thr protein kinases and phosphatases: Physiological roles and therapeutic potential. Biochimica et Biophysica Acta 1784(2008):193-202.

Xing, Z., W. Powell y Ch. Maynard. 1999. Development and germination of American chesnut somatic embryos. Plant Cell Tissue and Organ culture 57:47-55.

Zoglauer, K., U. Behrendt, A. Rahmat, H. Ross and Taryono. 2003. Somatic embryogenesis-the gate to biotechnology in conifers. In: M. Laimer, $M$. and W. Rucker (Eds.). Plant tissue culture. 100 years since Gottlieb Haberlandt. Springer. Austria. 260 p. 